\title{
A multiple criteria decision making technique for supplier selection and inventory management strategy: A case of multi-product and multi-supplier problem
}

\author{
Morteza Parhizkari $^{{ }^{*}}$, Maghsoud Amiri ${ }^{\mathrm{b}}$ and Morteza Mousakhani ${ }^{\mathrm{c}}$
}

${ }^{a}$ M.A. Student, Department of Mechanical and Industrial Engineering, Qazvin Branch, Islamic Azad University, Qazvin, Iran

${ }^{b}$ Associate Proff. \& Faculty Member, Department of Management, School of Management \& Accounting, Allameh Tabatabaee University, Tehran, Iran ${ }^{c}$ Department of Business Management, Faculty of Management and Economics, Science and Research branch, Islamic Azad University, Tehran, Iran

\section{H R O N I C L E}

Article history:

Received March 2, 2013

Received in Revised Format

April 1, 2013

Accepted April 10, 2013

Available online

April 112013

Keywords:

Supplier selection

NSGA-II

LP-Norm

Inventory management

\section{A B S T R A C T}

\begin{abstract}
Selection of an appropriate supplier along with planning a good inventory system has become an area of open research for the past few years. In this paper, we present a multi objective decision making supplier and inventory management model where two objectives including the quality and offering price of supplier are minimized, simultaneously. The proposed model is formulated as mixed integer programming and it is converted into an ordinary single objective function using Lp-Norm. In order to find efficient solution, we use NSGA-II as meta-heuristic technique and the performance of the proposed model is examined using some instances. The preliminary results indicate that both Lp-Norm and NSGA-II methods can be used to handle problems in various sizes.
\end{abstract}

\section{Introduction}

Supplier selection is one of the most important issues in any industry such as electronic producers, auto industries, etc. There are literally tremendous efforts to provide different techniques to locate appropriate suppliers and many of these techniques are involved with more than one single objective (Khodadadzadeh \& Sadjadi, S.J., 2013). An efficient and reliable supplier selection strategy reduces interruptions in production system, reduces the cost of ordering and increases the quality of products. Buffa and Ross (2011) performed a frontier perspective investigation to measure the consequences of using diverse supplier evaluation teams. Rabbani (2009) presented a new comprehensive framework for ranking accepted orders and supplier selection in make-to-order environments. Chen (2011) studied different structured methodology for supplier selection and evaluation in a supply chain. Lin et al. (2009) presented an integrated method for finding key suppliers in supply chain management (SCM).

* Corresponding author. +91-9611273853

E-mail addresses: morteza.parhizkari@yahoo.com (M. Parhizkari)

(C) 2013 Growing Science Ltd. All rights reserved.

doi: $10.5267 /$ j.dsl.2013.04.003 
Data Envelopment analysis (DEA) is one of the most popular techniques for supplier selection problem. Liu et al. (2000), for instance, used DEA technique to compare suppliers for supplier selection and performance improvement. Noorizadeh et al. (2013) implemented DEA crossefficiency evaluation for suppliers ranking in the presence of non-discretionary inputs. Ramanathan (2007) considered supplier selection problem by integrating DEA with the approaches of total cost of ownership and analytical hierarchy process (AHP). Toloo and Nalchigar (2011) presented a new DEA method for supplier selection in presence of both cardinal and ordinal data. Wen and Chi (2010) developed green supplier selection procedure based on the implementation of a DEA method. Wong and Wong (2007) measured the performance of supply chain using DEA modeling techniques. Xu et al. (2009) implemented rough DEA analysis and its application to supply chain performance evaluation.

In this paper, we present a new method to find appropriate suppliers using multi-objective technique. The proposed study of this paper first presents details of the proposed model in section 2 while details of solution strategies are given in section 3 and the paper ends with concluding remarks to summarize the contribution of the paper.

\section{The proposed model}

In this paper, we consider the availability of access to various suppliers and we plan to purchase an optimal level of goods from each supplier. Let $x_{i j}$, $w_{i j}$ and $p_{i j}$ be the amount of purchasing material, weight assigned for each supplier and offering price of part $i$ by supplier $j$, respectively. In addition, we consider different discount strategies for any supplier which is denoted by index $k$. Therefore, we plan to minimize the following two objectives,

$\min z_{1}=\sum_{i=1}^{m} \sum_{j=1}^{n} w_{i j} x_{i j}, \quad k \in K$

$\min z_{2}=\sum_{i=1}^{m} \sum_{j=1}^{n} \sum_{k=1}^{K} p_{i j k} x_{i j k}$,

where $x_{i j}=\sum_{k=1}^{K} x_{i j k}$. We consider a lower and upper limit for each supplier and once a supplier is selected, the order must be chosen within the acceptable limit. Let $y_{i j}$ be a binary variable as follows,

$$
\begin{aligned}
& y_{i j k}= \begin{cases}1 & x_{i j k}>0 \\
0 & x_{i j k}=0\end{cases} \\
& \sum_{k=1}^{K} y_{i j k} \leq 1
\end{aligned}
$$

Let $l_{i j k}$ and $u_{i j k}$ be the lower and upper limits for ordering product $i$ from supplier $j$ in discount order type $k$. Therefore, we have

$l_{i j k} y_{i j k} \leq x_{i j k} \leq y_{i j k} u_{i j k}$.

In order to simplify our problem formulation we consider a limit for each supplier as follows,

$\sum_{i=1}^{m} \sum_{j=1}^{n} \sum_{k=1}^{K} y_{i j k} \leq M$

where $M$ represents the maximum number of suppliers. The other constraints are associated with demand of part $i, D_{i}$ as follows,

$\sum_{j} x_{i j} \geq D_{i}, \quad i=1, \cdots, m$ 
In addition, since each product may require different number of parts, the following constraints must hold,

$\sum_{i} a_{i j} x_{i j} \leq C_{j} \cdot \quad j=1, \cdots, n$

The resulted problem is a mixed integer programming problem and when the number suppliers, products and discount strategies increase, it will become difficult to solve the resulted problem using a traditional method, efficiently. An alternative solution strategy is use metaheuristics to handle this issue. The proposed model of this paper uses NSGA-II method to solve the resulted model. Another issue is that we deal with a multi-objective problem statement and we need to cope with this issue, effectively. The proposed study of this paper uses Lp-Norm, which is a popular method for handling a multi-objective problem and generate Pareto-optimal solutions.

\section{Solution}

Deb et al. (2000) is believed to be the first who introduced the idea of non-dominated sorting genetic algorithm for multi-objective optimization known as NSGA-II method. Note that since we face with more than one optimal solution we need to handle multiple objective functions. Therefore, we demonstrate all efficient solutions in a set of Pareto optimal solutions.

Step 1: Chromosome setting: The structure of the chromosome is designed using a matrix where each element determines the amount of ordering product $i$ from supplier $j$.

Step 2: Evaluation: All generated solutions are evaluated based on objective functions.

Step 3: Divide solutions into two groups of dominated and non-dominated groups,

Step 4: Calculate design parameter: In this step, for each member of groups, we calculate a parameter to measure the distance from the other members of group.

Step 5: Make a strategy to select parents for the next generation,

Step 6: Perform two mutation and crossover operations to generate the new generation of solutions.

Fig. 1 shows details of step 6 for crossover operations as follows,

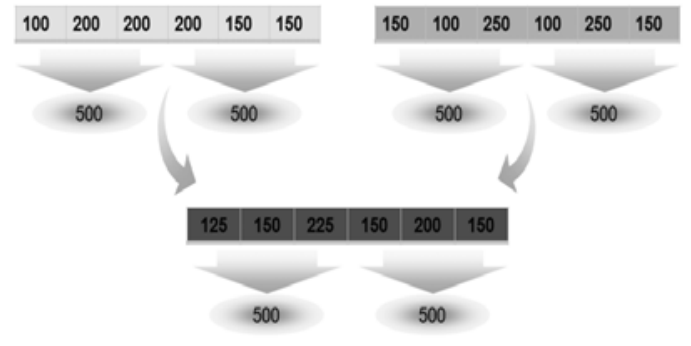

Fig. 1. Details of crossover

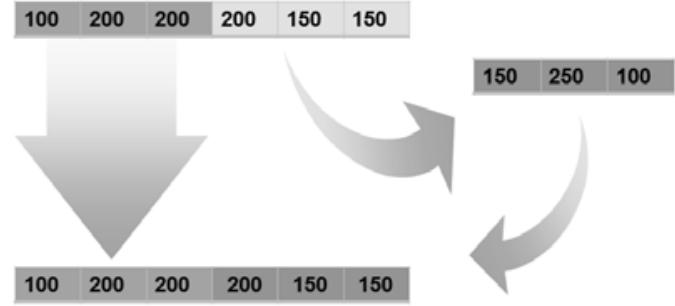

Fig. 2. Details of mutation

As we can observe from the results of Fig. 1, the members of two chromosomes are averaged and they are inserted into a new child chromosome. In addition, Fig. 2 demonstrates details of mutation operations used for the proposed study of this paper.

Step 7: Termination criteria: The proposed study of this paper uses Taguchi method to select appropriate numbers for various parameters.

Fig. 3 shows details of parameter setting based on Taguchi method. 


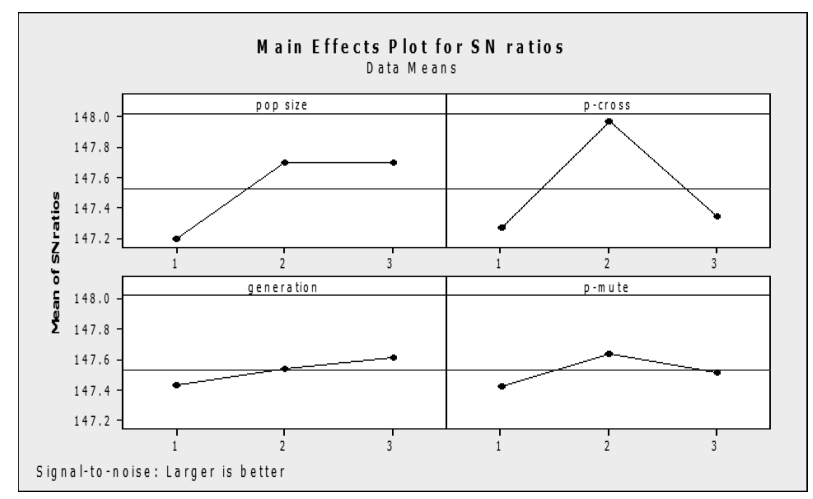

Fig. 3. The results of Taguchi method for parameter setting

In addition, Fig. 4 demonstrates details of the proposed model of this paper used for supplier selection problem.

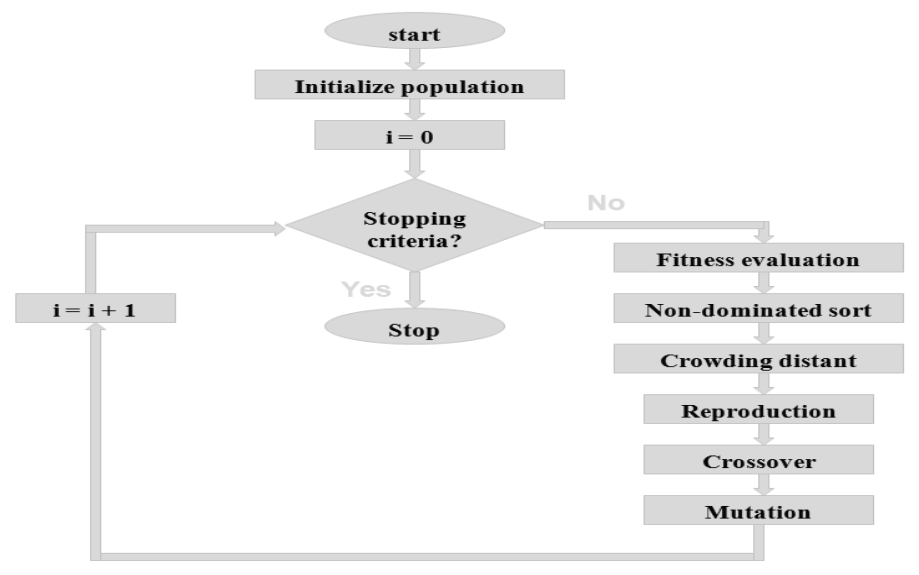

Fig. 4. The structure of the proposed model

\subsection{An example}

In this sub-section, we present details of the proposed study using an example consists of two products and three suppliers with three different discount strategies. Table 1 demonstrates details of input parameters.

\section{Table 1}

Input parameters

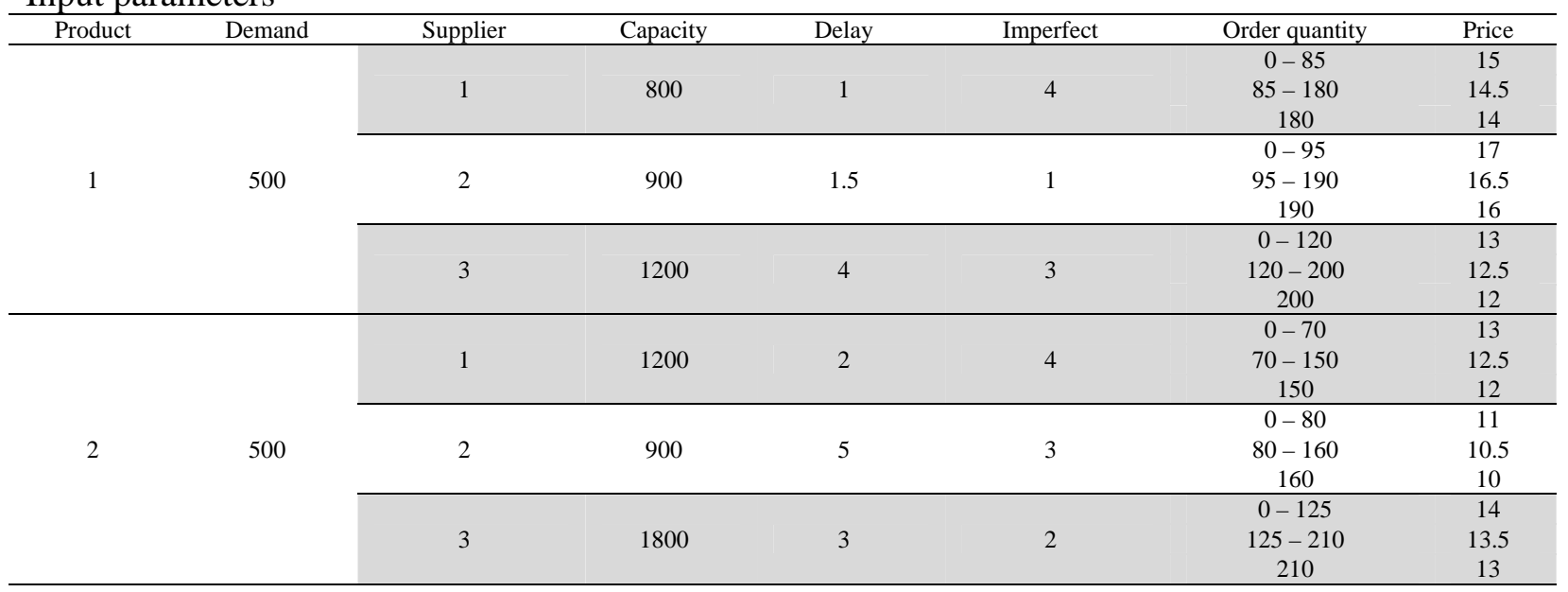




\subsection{Lp-Norm approach}

We first solve the problem using each objective function, separately. Table 2 shows details of our solutions generated.

Table 2

The results of optimal solutions

\begin{tabular}{ccc}
\hline & $\left(z_{1}\right)$ & $\left(z_{2}\right)$ \\
Variables & 439 & 11000 \\
\hline$x_{11}$ & 0 & 0 \\
$x_{12}$ & 500 & 0 \\
$x_{13}$ & 0 & 500 \\
$x_{21}$ & 0 & 0 \\
$x_{22}$ & 0 & 500 \\
$x_{23}$ & 500 & 0 \\
\hline
\end{tabular}

Now we use Lp-Norm by assigning different weights to $z_{1}$ and $z_{2}$ and Table 3 summarizes the results.

Table 3

Different Pareto solutions

\begin{tabular}{cccccccc}
\hline$x_{11}$ & $x_{12}$ & $x_{13}$ & $x_{21}$ & $x_{22}$ & $x_{23}$ & $z_{1}^{*}$ & $z_{2}^{*}$ \\
\hline 0 & 500 & 0 & 0 & 0 & 500 & 439 & 14500 \\
0 & 500 & 0 & 0 & 160 & 340 & 488 & 14020 \\
180 & 320 & 0 & 0 & 500 & 0 & 648 & 12640 \\
0 & 500 & 0 & 150 & 350 & 0 & 566.15 & 13300 \\
180 & 320 & 0 & 500 & 0 & 0 & 553.65 & 13730 \\
0 & 0 & 500 & 0 & 500 & 0 & 911 & 11000 \\
500 & 0 & 0 & 0 & 500 & 0 & 743 & 12000 \\
0 & 500 & 0 & 205 & 0 & 295 & 464.01 & 14295 \\
\hline
\end{tabular}

\subsection{NSGA-II}

The proposed NSGA-II generates different Pareto-optimal solutions, which means we do not need to use Lp-Norm method. Applying the NSGA-II method presented in section 2 yields the following Pareto-optimal solutions. In addition, Fig. 5 demonstrates Pareto optimal solution values.

\section{Table 4}

The results of some Pareto optimal solutions

\begin{tabular}{cccccl}
\hline $\mathrm{x}_{11}$ & $\mathrm{x}_{12}$ & $\mathrm{x}_{13}$ & $\mathrm{x}_{21}$ & $\mathrm{x}_{22}$ & $\mathrm{x}_{23}$ \\
\hline 0 & 500 & 0 & 0 & 0 & 500 \\
193 & 307 & 0 & 0 & 500 & 0 \\
0 & 0 & 500 & 0 & 500 & 0 \\
207 & 0 & 293 & 0 & 470 & 30 \\
207 & 0 & 293 & 193 & 307 & 0 \\
500 & 0 & 0 & 0 & 500 & 0 \\
391 & 0 & 109 & 27 & 473 & 0 \\
0 & 500 & 0 & 163 & 203 & 134 \\
0 & 293 & 207 & 27 & 473 & 0 \\
27 & 473 & 0 & 0 & 109 & 391 \\
0 & 0 & 500 & 174 & 326 & 0 \\
500 & 0 & 0 & 193 & 307 & 0 \\
\hline
\end{tabular}

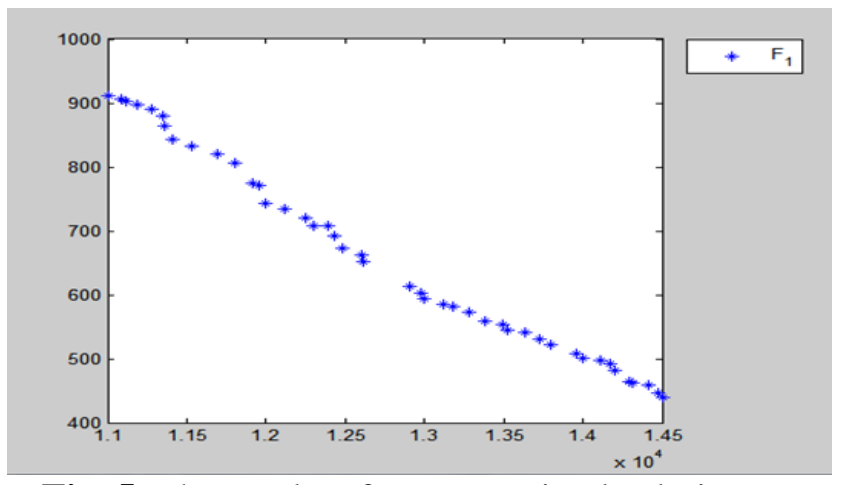

Fig. 5. The results of Pareto optimal solutions

As we can observe from the results of Fig. 5, two objectives are in serious conflict and as one objective is getting worse we may get better results for the other objective function. 


\section{Conclusion}

In this paper, we have proposed a new supplier selection problem formulated as mixed integer programming with two objectives. The proposed model was first solved using Lp-Norm and then it was solved using NSGA-II to find different Pareto solutions. The implementation of the proposed model was examined using both approaches, Lp-Norm and NSGA-II. We believe both methods are useful, the first method, Lp-Norm, is useful when there is a limited number of suppliers and the second method can be used when we face with large numbers of products and suppliers.

\section{References}

Buffa, F.P., \& Ross A.D. (2011). Measuring the consequences of using diverse supplier evaluation teams: A performance frontier perspective. Journal of Business Logistics, 32(1), 55-68.

Chen, Y.J. (2011). Structured methodology for supplier selection and evaluation in a supply chain. Information Sciences, 181(9), 1651-1670.

Deb, K., Agrawal, S., Pratap, A., Meyarivan, T. (2000). A fast elitist non-dominated sorting genetic algorithm for multi-objective optimization: NSGA-II. In: proceedings of the parallel problem solving from nature VI (PPSN-VI) conference, 849-858.

Lin, R.H., Chuang, C.L., Liou, J.H., \& Wu, G.D. (2009). An integrated method for finding key suppliers in SCM. Expert Systems with Applications, 36(3), 6461-6465.

Liu, J., Ding, F.Y., \& Lall, V. (2000). Using data envelopment analysis to compare suppliers for supplier selection and performance improvement. Supply Chain Management: An International Journal, 5(3), 143-150.

Khodadadzadeh, T., \& Sadjadi, S.J. (2013). A state-of-art review on supplier selection problem. Decision Science Letters, 2(1), 59-70.

Noorizadeh, A., Mahdiloo, M., \& Farzipoor Saen, F. (2013). Using DEA cross-efficiency evaluation for suppliers ranking in the presence of non-discretionary inputs. International Journal of Shipping and Transport Logistics, 5(1), 95-111.

Rabbani, M. (2009). A new comprehensive framework for ranking accepted orders and supplier selection in make-to-order environments. Computers \& Industrial Engineering, 919-924.

Ramanathan, R. (2007). Supplier selection problem: integrating DEA with the approaches of total cost of ownership and AHP. Supply Chain Management: An International Journal, 12(4), 494509.

Toloo, M., \& Nalchigar, S. (2011). A new DEA method for supplier selection in presence of both cardinal and ordinal data. Expert Systems with Applications, 38(12), 14726-14731.

Wen, U.P., \& Chi, J.M. (2010). Developing green supplier selection procedure: A DEA approach. Industrial Engineering and Engineering Management (IE\&EM), 70-74.

Wong, W.p., \& Wong, K.Y. (2007). Supply chain performance measurement system using DEA modeling. Industrial Management \& Data Systems. 107(3). 361-381.

Xu, J., Li, B., \& Wu, D. (2009). Rough data envelopment analysis and its application to supply chain performance evaluation. International Journal of Production Economics, 122(2), 628-638. 